Military Technical College Kobry El-Kobbah, Cairo, Egypt

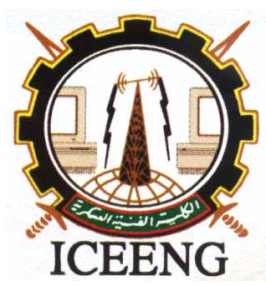

\author{
$6^{\text {th }}$ International Conference \\ on Electrical Engineering \\ ICEENG 2008
}

\title{
Micro strip RF band-pass filter for user equipment W-CDMA receiver
}

\section{By}

Wael M. Abdullah*

wm3@ieee.org

\author{
Yahia M. El-Sayed* \\ yahia.muhammad2@gmail.com
}

\section{Abstract:}

Microstrip structures are easy to fabricate and reveal effective success in RF distributed circuits such as RF filters. In this paper, the RF filter of the user equipment (UE) WCDMA receiver $\left(\mathrm{f}_{0}=2.14 \mathrm{GHz}\right.$ and $\left.\mathrm{BW}=60 \mathrm{MHz}\right)$ is to be designed via applying three different techniques; namely: the traditional parallel coupled lines method, edgecoupled hairpin structure and the microstrip ring resonator method. In each case minimizing the area is a goal. Two different types of the commercial substrates will be used. Circuit and electromagnetic (EM) simulations will be accomplished using the Agilent tool Advanced Design System (ADS) that uses the Momentum method in the EM simulation. Local implementation of the designed microstrip circuits is a target.

\section{Keywords:}

Microstrip, Bandpass, Filter, Hairpin, Coupled Lines, Ring Resonator.

* Ain Shams University, Faculty of Engineering, Electronics \& Comm. Eng. Dept., Cairo, Egypt. IEEE Student Member. 


\section{Introduction:}

Filters are basic building blocks in communication systems to select certain band and reject another. At RF and microwaves, lumped components fail to build filters and distributed components must be used to form RF filters. There are many types of distributed components to be used to build a filter such as strip line, microstrip, coplanar waveguide and others. Dielectric resonators may be used as well.

RF filters design, usually, done by three steps namely; designing the so-called low-pass prototype (LPF with cutoff of 1 radian per second and input and output impedances of 1 $\mathrm{Ohm}$ ), converting the prototype to the targeted type, then applying frequency and impedance scaling to match the required input and output impedances and cutoff frequency. After these steps the reactive elements are to be transformed to distributed elements (microstrip lines are more pronounced and will be used). The methods of designing the low-pass prototype for any filter type are demonstrated in [1] and [2].

\section{Targeted Specifications:}

The required filter is the RF filter used in the W-CDMA UE receiver front-end that works in the frequency range of $2110 \mathrm{MHz} \ddagger 2170 \mathrm{MHz}$. The attenuation of the filter in the stop-band is required to be in order of $40 \mathrm{~dB}$ in the transmitter frequency band of the system that is $1920 \mathrm{MHz} \ddagger 1980 \mathrm{MHz}$ and the pass-band insertion loss is less than $3 \mathrm{~dB}$ (this is like the commercials SAW filter designed for the W-CDMA UE receiver). So the complete specifications of the filter may be summarized as follows:

- $\mathrm{f}_{0}=2.14 \mathrm{GHz}, \mathrm{BW}=60 \mathrm{MHz} \ddagger \Delta=0.028$

- $\mathrm{Z}_{0}=50 \Omega$

- Attenuation > 40dB @ $1920 \mathrm{MHz} \ddagger 1980 \mathrm{MHz}$.

- Small area is required

where $\mathrm{f}_{0}$ is the center frequency, BW is the bandwidth of the filter, $\Delta$ is the percentage bandwidth and $\mathrm{Z}_{0}$ is the input (and/ or output) impedance of the filter structure.

\section{Parallel Coupled Lines Filter:}

The parallel coupled lines transmission lines can be used to construct directional couples and many types of passive filters. Fabrication of multi-section band-pass or band-stop 
coupled lines filters is particularly easy in microstrip technology for bandwidth less than about $20 \%$.

From the given specifications, the required filter must have a relatively high cutoff rate. So, an equal-ripple Chebyshev response is chosen because it is the sharpest response and the pass-band ripples are to be chosen in order of $0.5 \mathrm{~dB}$. The given stop-band attenuation obliges a filter order more than 3. Since minimum area is targeted, then a 3rd-order equal-0.5 dB-ripple BPF is to be designed, but this will give a small deviation beyond the required stop-band attenuation. The design methodology id typically like stated in [3].

A ceramic substrate with relatively high dielectric constant and small losses was chosen in order to minimize the dimensions of the coupled lines sections and the insertion loss. The used substrate is the commercial 99_alumina by Accumet, it has $\varepsilon_{\mathrm{r}}=9.9, \mathrm{~h}=10$ mils and $\tan (\delta)=0.0001$. The ceramic substrate needs special and hard techniques to cut such as using diamond or laser equipments. So, it is better to consider the available substrate dimensions in the design procedure. From the available ceramic substrates are $2 " \times 2 "$ $(5 \mathrm{~cm} \times 5 \mathrm{~cm})$ and $1 " \times 1 "(2.5 \mathrm{~cm} \times 2.5 \mathrm{~cm})$. That's why a 3 rd-order filter was considered fitting the $2 " \times 2 "$ substrate.

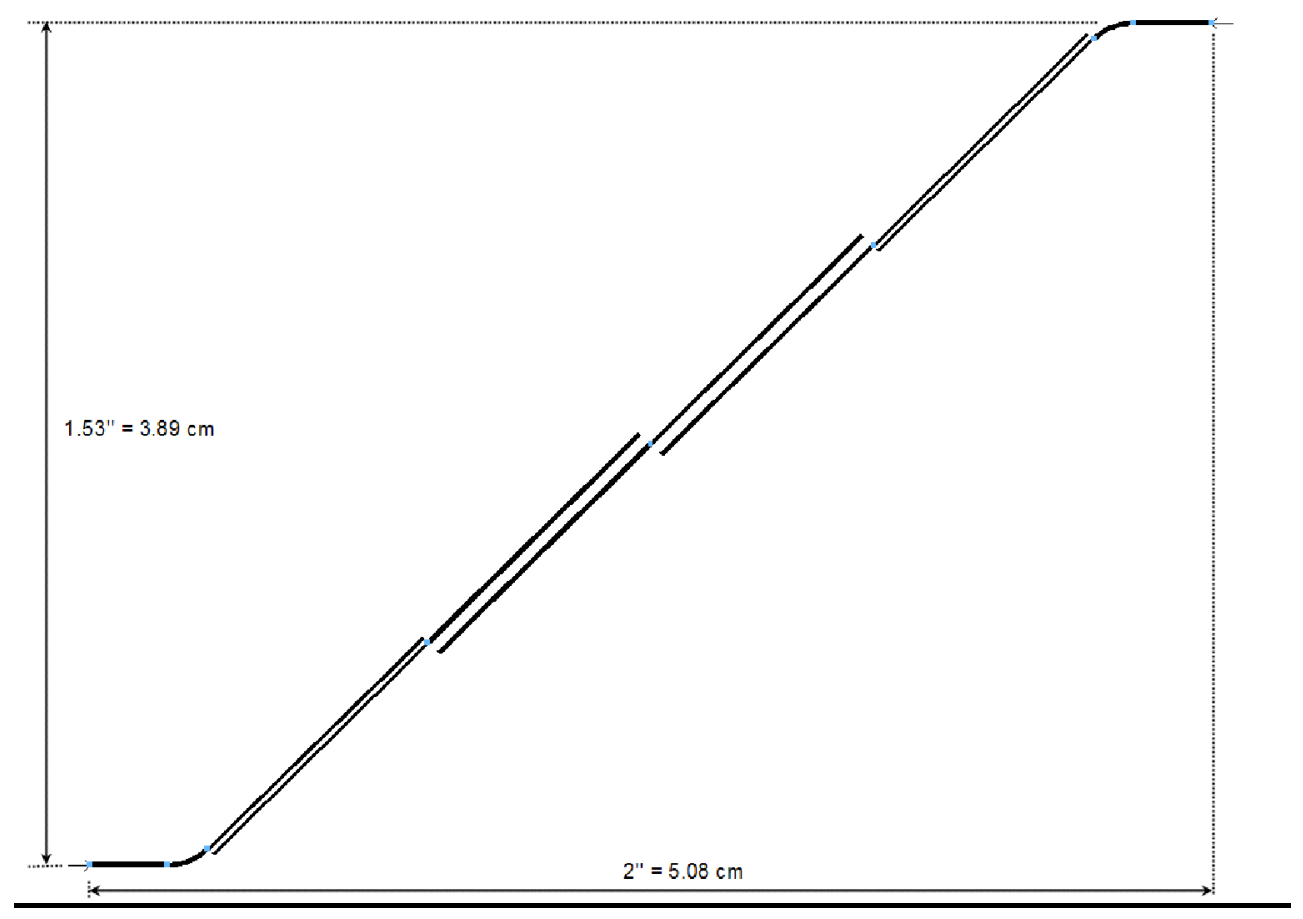

Figure (1): Parallel Coupled Lines Filter Layout 
The simulation results of the designed filter, after the optimization has been done to meet the required specifications, are shown in Fig. 2 and Fig. 3. Both circuit and electromagnetic (using Momentum method) simulations results are shown in the figures. The response of the filter in the circuit simulation was intentionally broadened to the right in order to obtain a satisfied response on the Momentum simulation as shown in the figures.

The obtained characteristics of the coupled lines filter from the EM simulation are summarized as follows:

- Pass-band attenuation at $2140 \mathrm{MHz}\left(\mathrm{f}_{0}\right.$ of $\left.\mathrm{Rx}\right)$ is $3.5 \mathrm{~dB}$.

- Stop-band attenuation at $1950 \mathrm{MHz}\left(\mathrm{f}_{0}\right.$ of $\mathrm{Tx}$ ) is $36 \mathrm{~dB}$.

- Return loss at $2140 \mathrm{MHz}\left(\mathrm{f}_{0}\right.$ of $\mathrm{Rx}$ ) is $17 \mathrm{~dB}$.

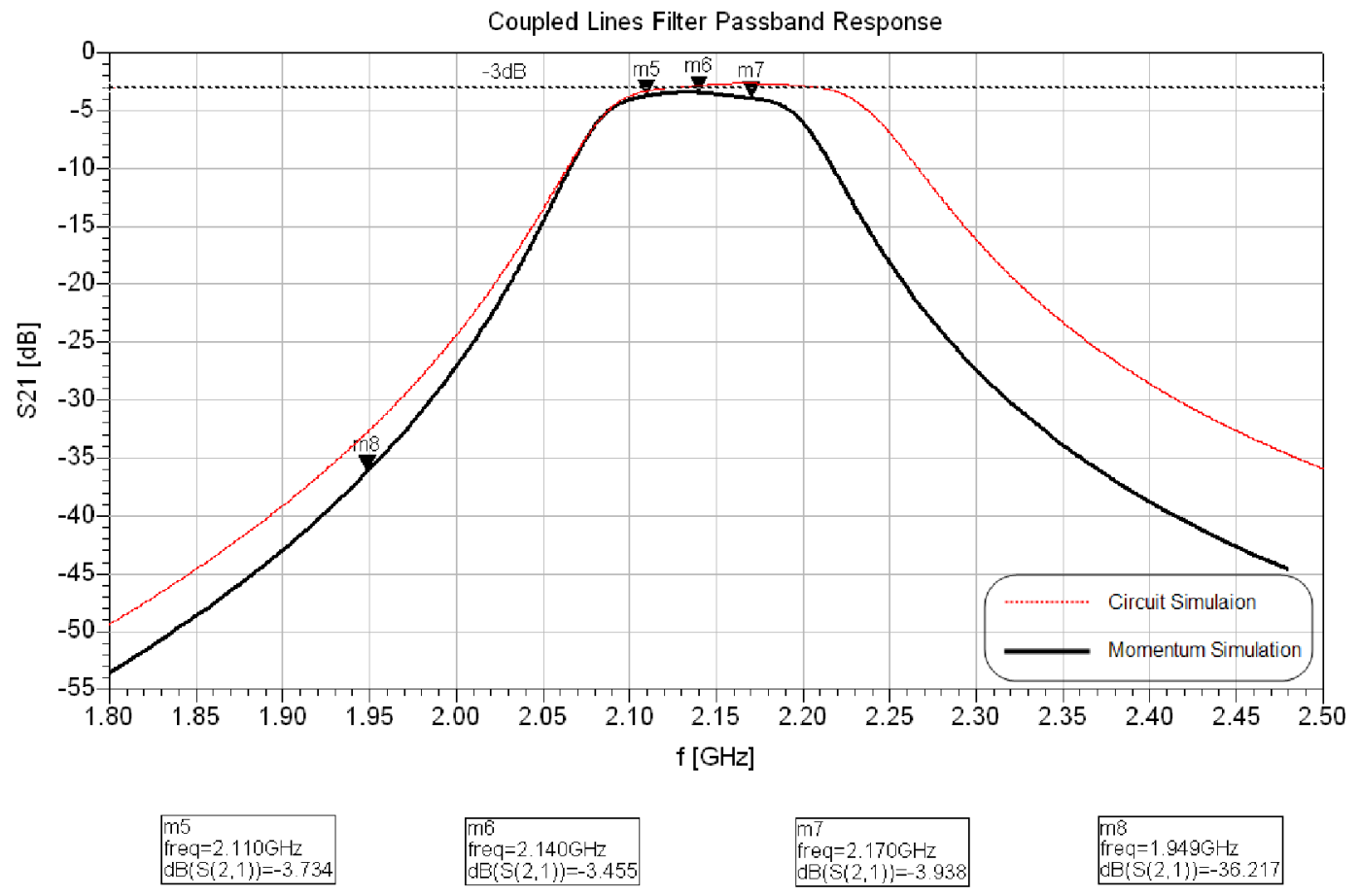

Figure (2): Coupled lines filter insertion loss characteristics 


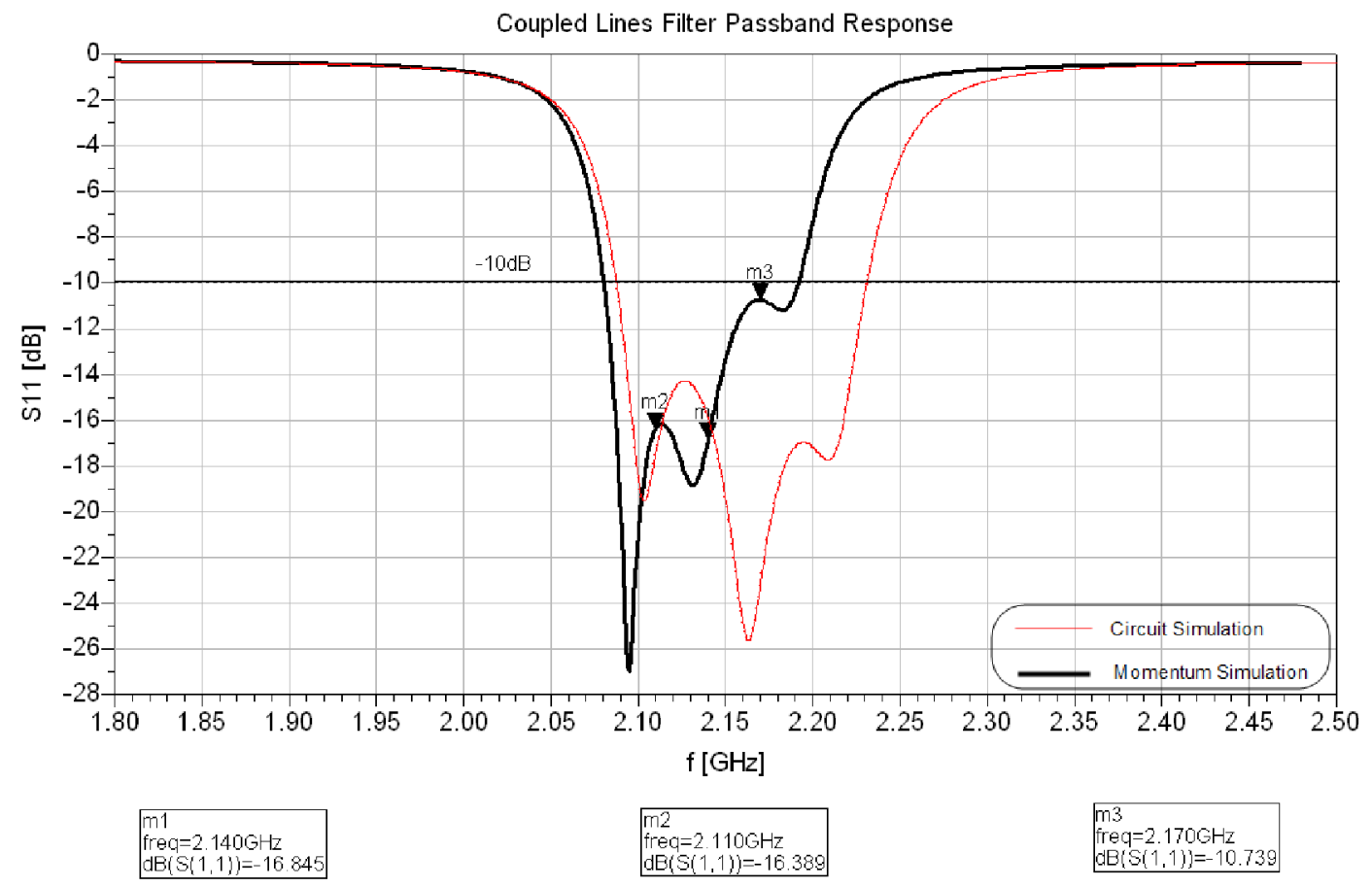

Figure (3): Coupled lines filter return loss characteristics

\section{Hairpin Filter:}

The hairpin filter is particularly well suited for microstrip and TEM printed-circuit realizations because grounding of the filter resonators is generally not required [5].

The hairpin filter configuration is derived from the half wave edge-coupled filter. To improve the aspect ratio, the resonators are folded into (U) shape, each of the U-shaped structure is called hairpin resonator, each resonator is 180 degrees $(\lambda / 2)$ electrical length so that the length from the center to either ends is 90 degrees ( $\lambda / 4)$ degrees (Fig. 4).

For the hairpin filter, we chose to design the filter on the commercial Teflon RT/Duroid 6010 substrate with the following specifications: $\varepsilon_{\mathrm{r}}=10.5, \mathrm{~h}=25$ mils, $\tan (\delta)=0.0015$ and thermal conductivity $=0.0041$.

We need a filter to pass frequencies from $2.11 \mathrm{GHz}$ up to $2.17 \mathrm{GHz}$ (center frequency is $2.14 \mathrm{GHz}$ and band width $60 \mathrm{MHz}$ ), it was found that a fifth order Chebyshev response filter will be sufficient for this fractional band width (0.028). 


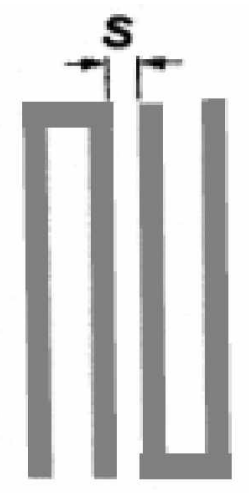

Figure (4): Hairpin resonator section

Using the prototype table for $0.1 \mathrm{~dB}$ equal-ripple Chebyshev filter given by [6], the filter parameters are easily got from which the physical dimensions are calculated.

The final layout after optimizing the design for the required specs is depicted in Fig. 5. Fig. 6 and Fig. 7 show the insertion loss and return loss characteristics of the filter respectively.

The obtained characteristics of the hairpin filter from the EM simulation are:

-Pass-band attenuation at $2140 \mathrm{MHz}\left(\mathrm{f}_{0}\right.$ of $\left.\mathrm{Rx}\right)$ is $0 \mathrm{~dB}$.

-Stop-band attenuation at $1950 \mathrm{MHz}$ ( $\mathrm{f}_{0}$ of $\mathrm{Tx}$ ) is $32 \mathrm{~dB}$.

- Return loss at $2140 \mathrm{MHz}\left(\mathrm{f}_{0}\right.$ of $\mathrm{Rx}$ ) is $26 \mathrm{~dB}$.

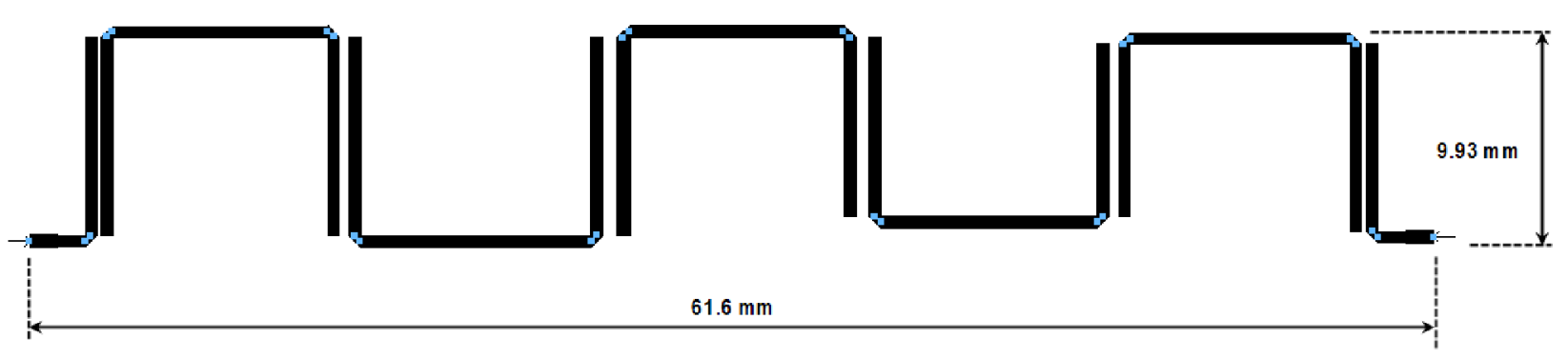

Figure (5): Hairpin filter layout 


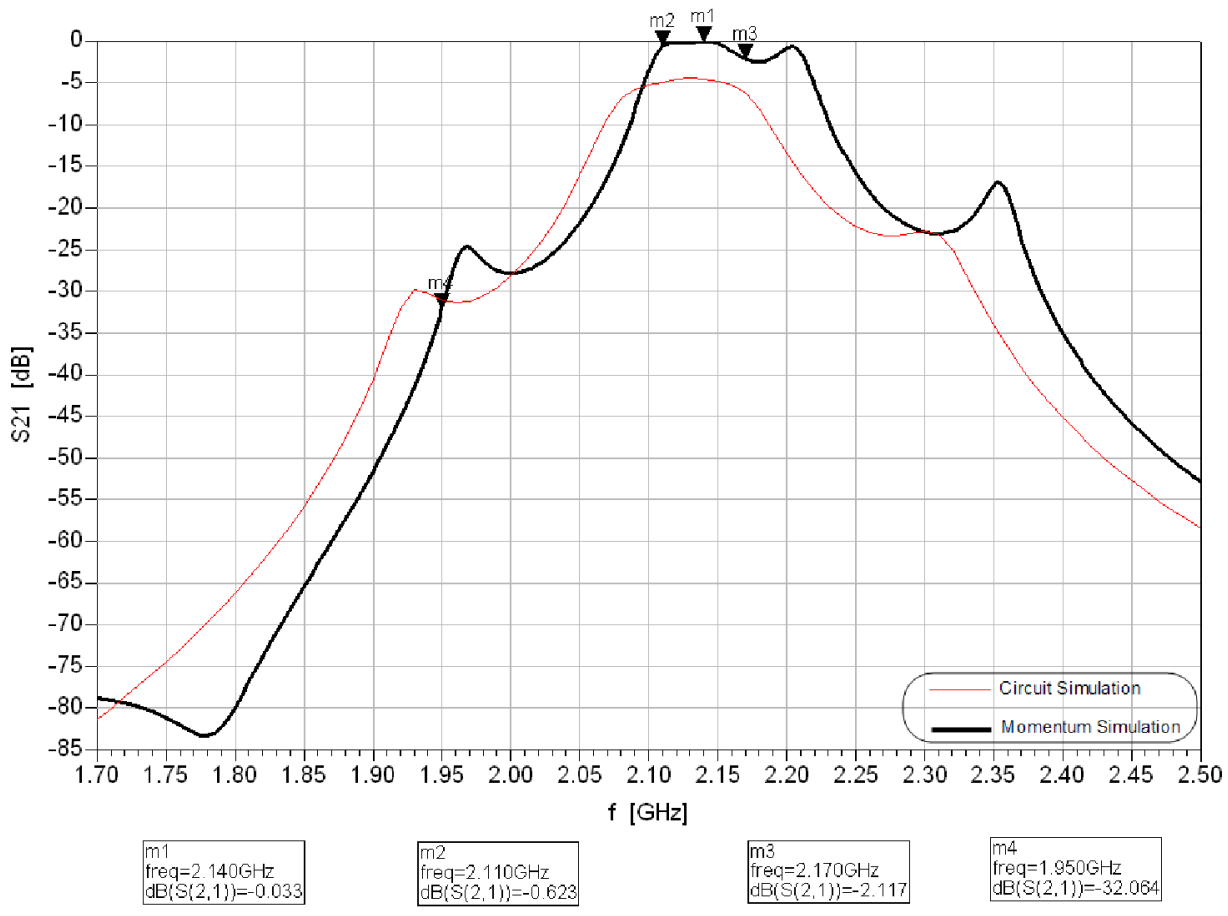

Figure (6): Hairpin filter insertion loss characteristics

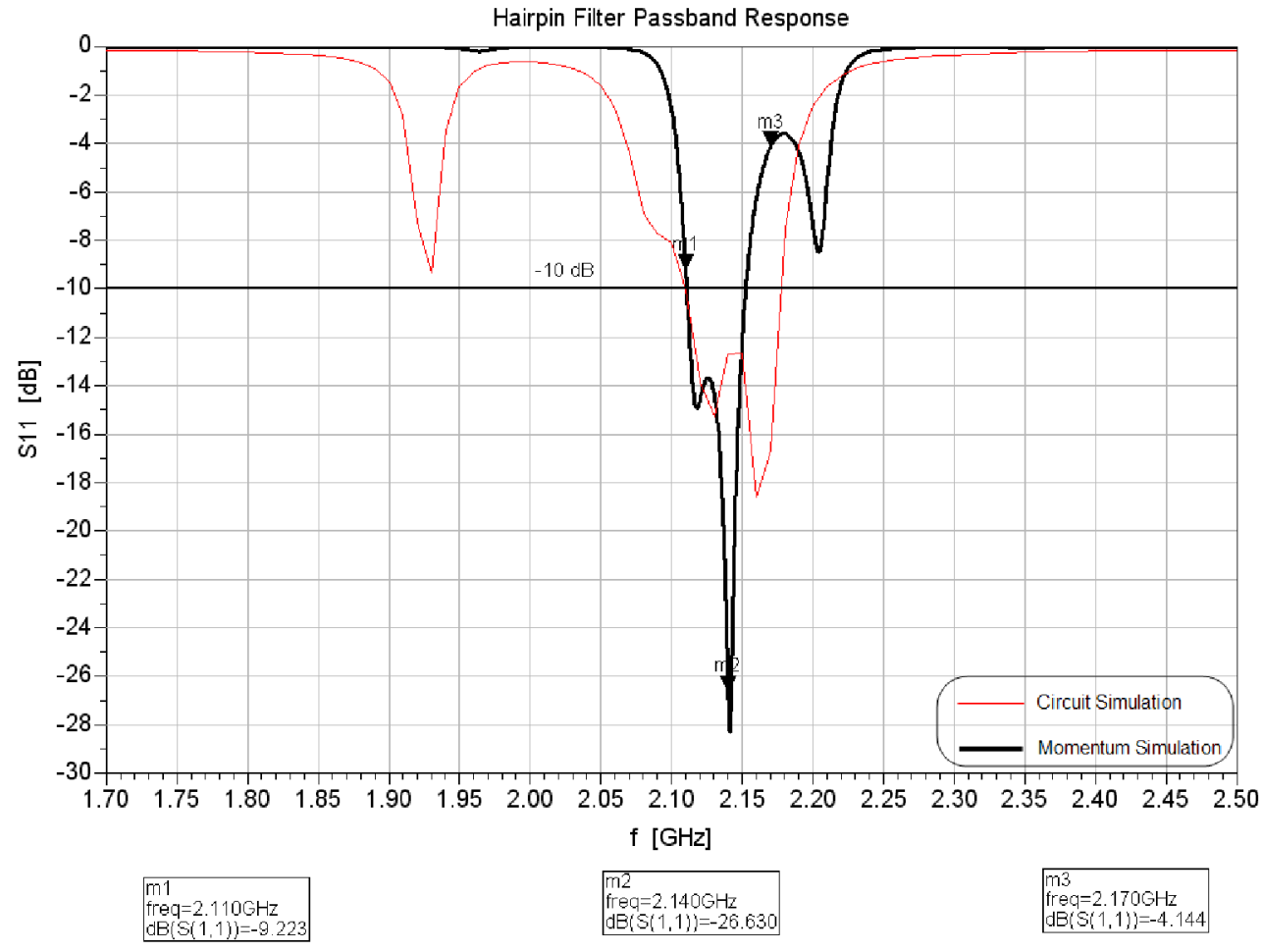

Figure (7): Hairpin filter return loss characteristics 


\section{Ring Resonator Filter:}

The ring resonator is a simple circuit with various shapes. For filter application, it may take the shape depicted in Fig. 8; where the width of the 45 degrees controls the filter action. The structure would only support waves that have an integral multiple of the guided wavelength equal the mean circumference. The circuit is simple and easy to built using the microstrip technology, however, many more complicated circuits can be created by cutting a slit, adding a notch, cascading two or more rings, implementing some solid-state devices, integrating with input and output lines, and so on.

When the mean circumference of the ring resonator is equal to an integral multiple of a guided wavelength, resonance is established.

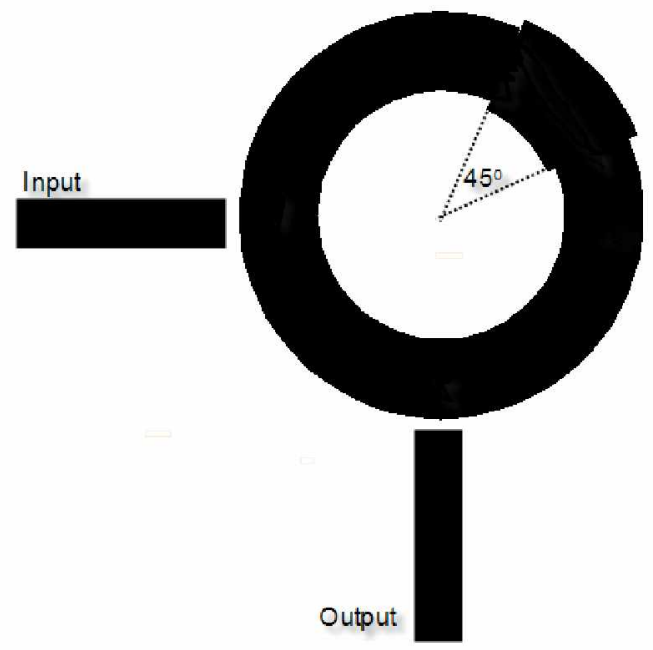

Figure (8): Microstrip ring resonator filter structure

Many models have been reported in literature for the analysis of the ring resonator circuits, such as Magnetic Wall model, Transmission Line model, Distributed Transmission Line model and others [6].

Again the commercial ceramic substrate 99_alumina by Accumet $\left(\varepsilon_{\mathrm{r}}=9.9, \mathrm{~h}=25\right.$ mils and $\tan (\delta)=0.0001$ ) is used targeting lower loss and area.

The radius of the ring that corresponds to the required center frequency, that is 2140 $\mathrm{MHz}$, occupies all the area of the $1 " \times 1 "$ substrate. So, $2 " \times 2 "$ substrate is used to add the input and output feed line with sufficient length to set up the SMA connectors. 
For lower insertion loss, the coupling gaps at the input and the output were eliminated. This is typically in filter applications.

The final layout of the ring resonator filter after optimizing the dimensions for the required specification using the ADS is given in Fig. 9 and its corresponding circuit and EM simulations for both insertion loss characteristics and return loss characteristics are given in Fig. 10 and Fig. 11 respectively.

The obtained characteristics of the ring resonator filter from the electromagnetic simulation are:

- Pass-band attenuation at $2140 \mathrm{MHz}\left(\mathrm{f}_{0}\right.$ of $\left.\mathrm{Rx}\right)$ is $0.7 \mathrm{~dB}$.

- Stop-band attenuation at $1950 \mathrm{MHz}\left(\mathrm{f}_{0}\right.$ of Tx) is $23 \mathrm{~dB}$.

- Return loss at $2140 \mathrm{MHz}\left(\mathrm{f}_{0}\right.$ of $\mathrm{Rx}$ ) is $20 \mathrm{~dB}$.

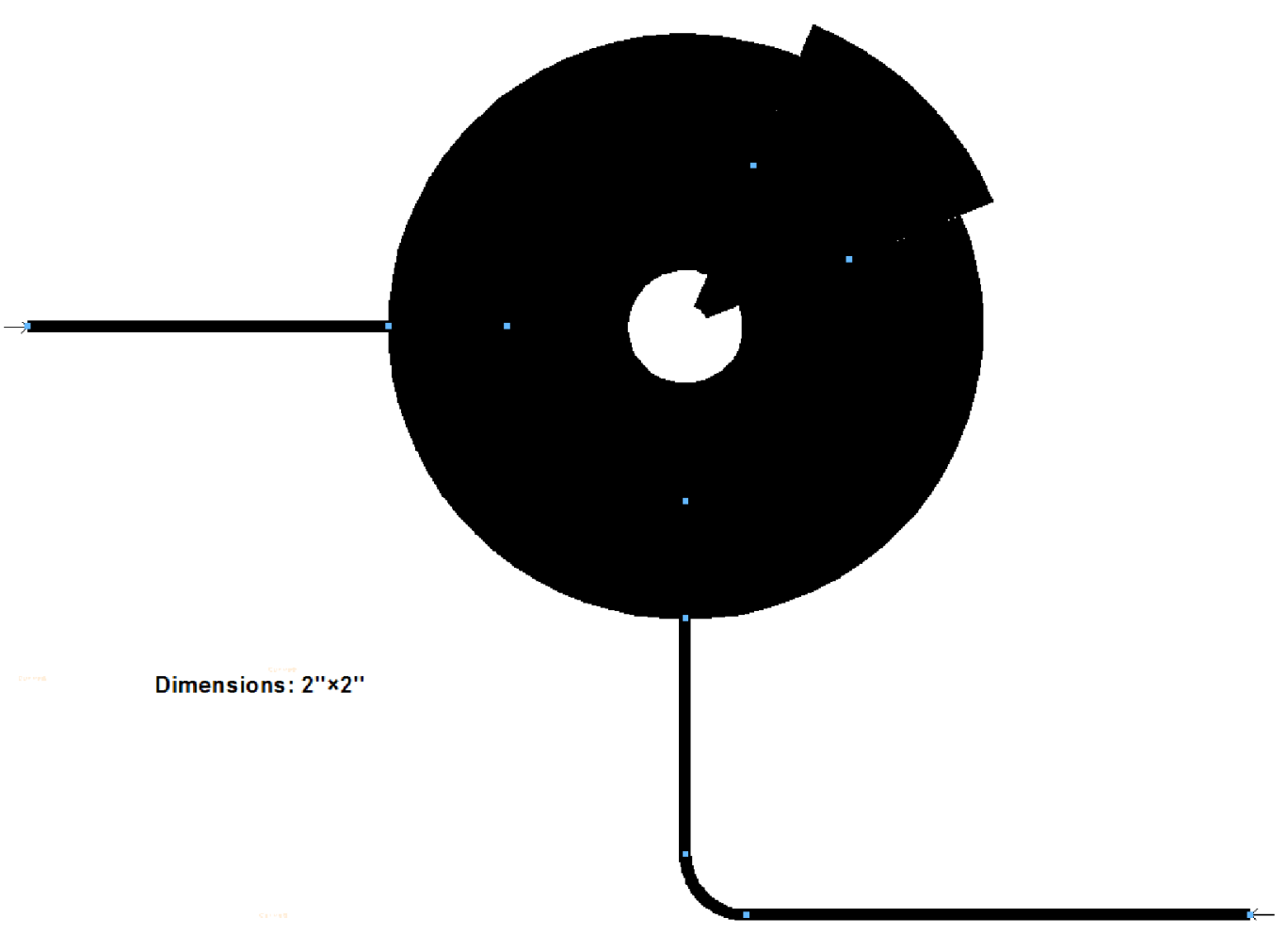

Figure (9): Ring resonator filter layout 

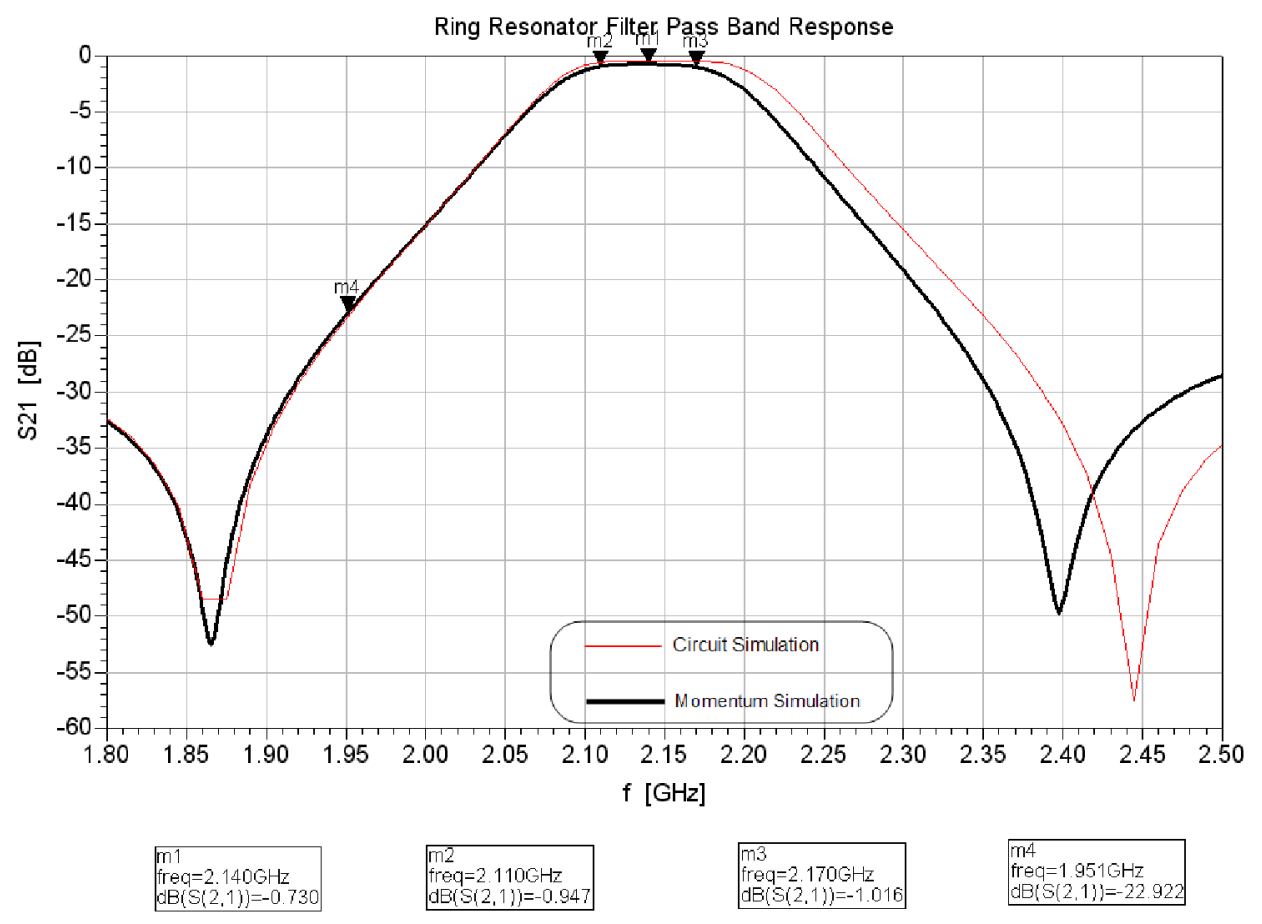

Figure (10): Ring resonator filter insertion loss characteristics

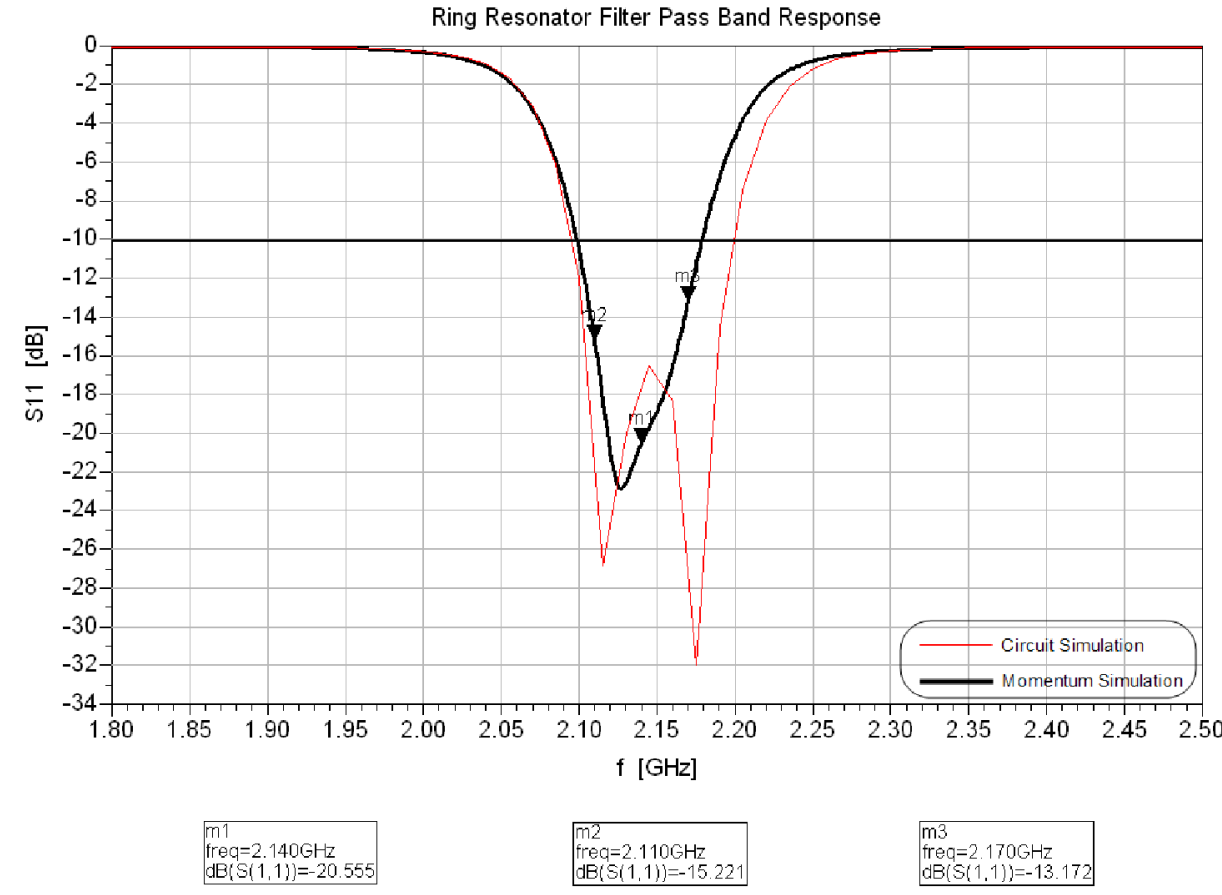

Figure (11): Ring resonator filter return loss characteristics 


\section{Implementation:}

One of the major objectives of this work is to encourage such microstrip technology manufacturing in Egypt. The hair-pin filter was manufactured and measured showing not-bad results compared to the EM simulation results. The ring resonator filter still in its manufacturing phase where its photolithography mask was built till now. The parallel coupled lines filter was not implemented because its substrate could not be obtained.

The measured results of the hair-pin filter are displayed below. Fig. 12 shows the broadband response while Fig. 13 shows the passband response.

Comparing with the EM simulation results, one can notice shift in the center frequency from $2.14 \mathrm{GHz} \ddagger 2.06 \mathrm{GHz}$, extending the $\mathrm{BW}$ from $60 \mathrm{MHz} \ddagger 127 \mathrm{MHz}$ and insertion loss at $\mathrm{f}_{0}$ of $2.8 \mathrm{~dB}$ instead of $0 \mathrm{~dB}$.

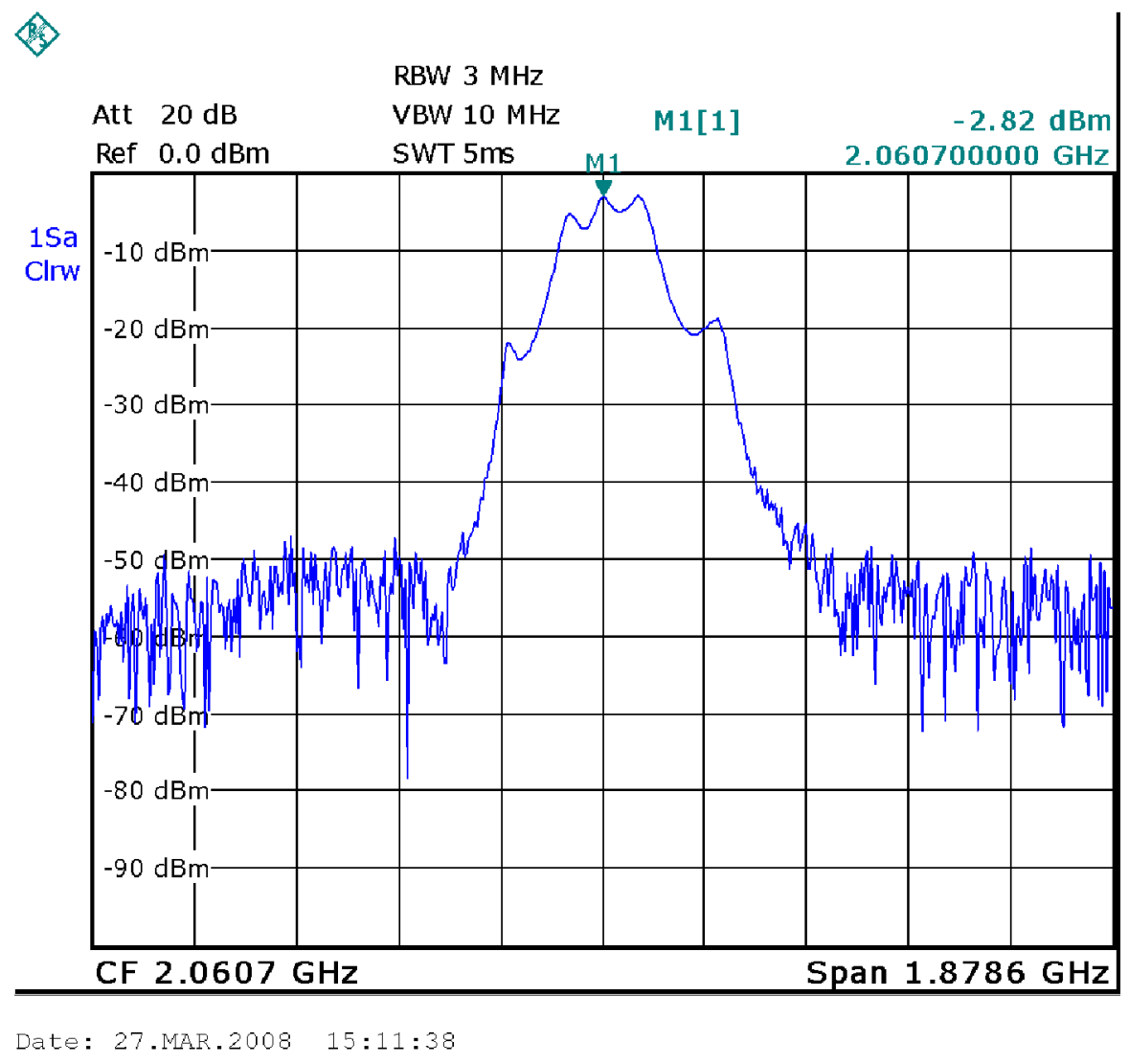

Figure (12): Hair-pin filter measured broadband response 


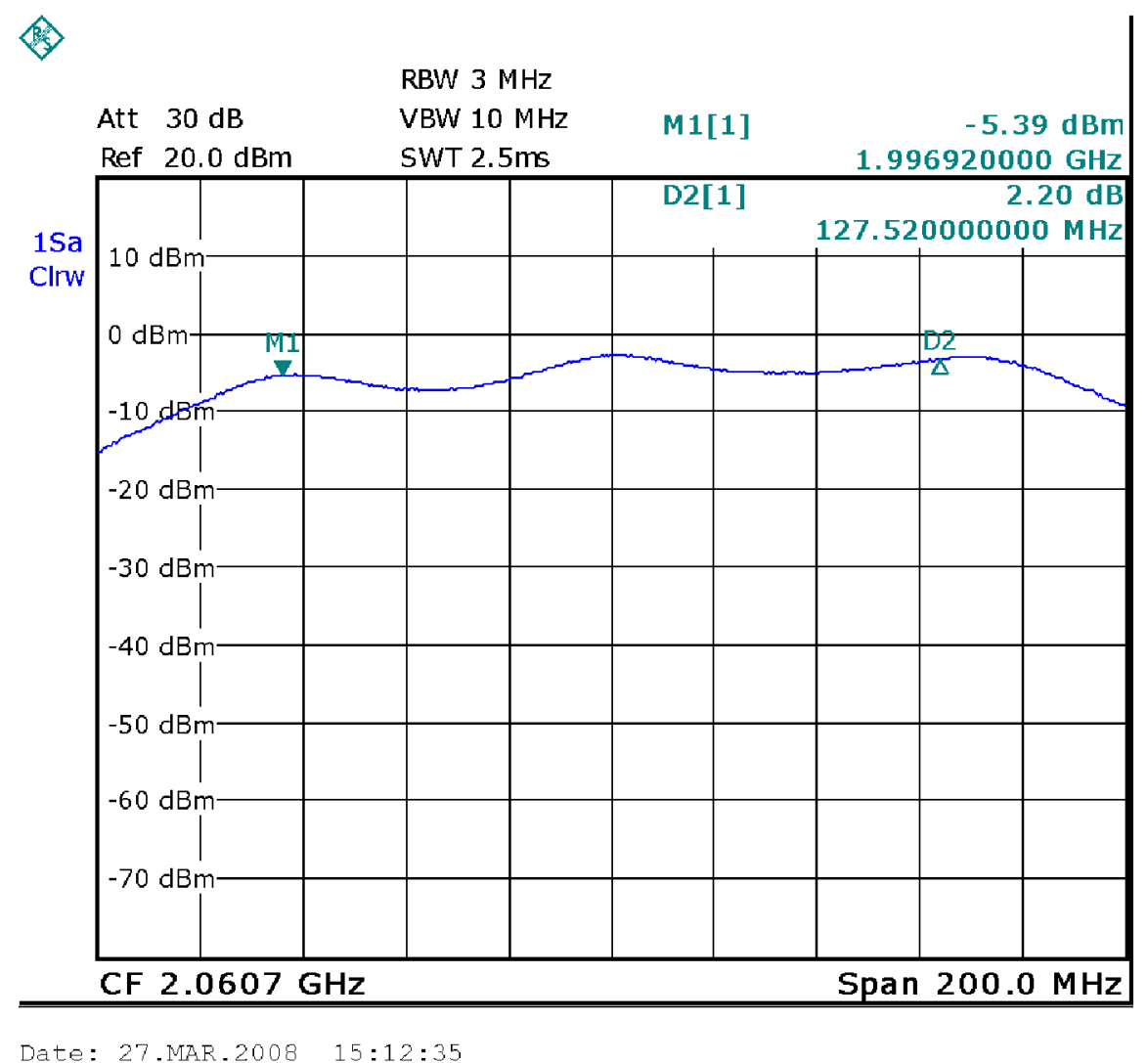

Figure (13): Hair-pin filter measured passband response

\section{Conclusion:}

A $60 \mathrm{MHz}$ RF band-pass filter was designed and simulated at $2.14 \mathrm{GHz}$ using three different techniques namely, coupled lines filter, hair-pin filter and microstrip ring resonator filter. The commercial high- $\varepsilon_{\mathrm{r}}$ ceramic substrate was used in order to minimize the physical dimensions of the transmission lines in the coupled lines and ring resonator filters while the Teflon substrate was used in the hair-pin filter.

It was required to obtain results as near as possible from the response of the commercial SAW filters. Table 1 compares among the designed three filters.

It was expected that the ceramic substrate gives lower insertion loss than that due the Teflon substrate. This has been achieved in the ring resonator filter but not in the coupled lines filter.

The hair-pin filter was manufactured, tested and shows acceptable results. The other two filters are being manufacturing as a future work. 
TABLE (1): COMPARISON AMONG THE THREE FILTERS RESPONSES

\begin{tabular}{l|l|l|l}
\hline \hline \multicolumn{1}{c}{ Specification } & \multicolumn{1}{c}{ Coupled Lines } & \multicolumn{1}{c}{ Hairpin } & \multicolumn{1}{c}{ Ring Resonator } \\
\hline $\mathbf{f}_{\mathbf{0}}$ & $2.14 \mathrm{GHz}$ & $2.14 \mathrm{GHz}$ & $2.14 \mathrm{GHz}$ \\
Usable BW & $\sim 60 \mathrm{MHz}$ & $60 \mathrm{MHz}$ & $60 \mathrm{MHz}$ \\
IL @ f $\mathbf{f}_{\mathbf{0}}$ & $3.5 \mathrm{~dB}$ & $0 \mathrm{~dB}$ & 0.7 \\
RL @ f & $17 \mathrm{~dB}$ & $26 \mathrm{~dB}$ & 20 \\
Att. @ 1950 MHz & $36 \mathrm{~dB}$ & $32 \mathrm{~dB}$ & 23 \\
Dimensions & $5 \mathrm{~cm} \times 3.9 \mathrm{~cm}$ & $6.1 \mathrm{~cm} \times 1 \mathrm{~cm}$ & $2.45 \mathrm{~cm} \times 2.45 \mathrm{~cm}$ \\
\hline \hline
\end{tabular}

\section{Acknowledgement:}

This work was supported in part by Nahdet El-Mahrousa who we deeply appreciate and acknowledge. [http://www.nahdetmasr.org/yia]

The author thanks Dr. Ayman El-Tager, Military Technical College, Cairo, Egypt, for his infinite support and guidance during this work; in both design and implementation phases.

\section{References:}

[1] Jia-Sheng Hong, M. J. Lancaster, Microstrip Filters for RF-Microwave Application, Lancaster, 2001.

[2] David M. Pozar, Microwave Engineering, 2nd Edition, John Wiley \& Sons Inc., 1998.

[3] David M. Pozar, Microwave and RF Design of Wireless Systems, John Wiley \& Sons Inc., 2001.

[4] Amr M. Ezzat Safwat, Ain Shams University, Electromagnetics Lecture Notes, 2006.

[5] G. Cristal, and Sidney Frankel, Hairpin Line and Hybrid Hairpin Hine/ Half-wave Parallelcoupled Line Filter, IEEE Vol. MTT, No 11, November 1972.

[6] Kai Chang, Microwave Ring Circuits and Antennas, John Wiley \$ Sons Inc., 1996.

[7] Matthaei, L. Young and E. M. T. Jones, Microwave Filters, Impedance Matching Networks and Coupling Structures, Boston, MA: Artech House, 1980.

[8] ADS2005A Help, Agilent Technology Inc. 